\title{
Los senderos tortuosos de América Latina*
}

* Herrera Mejía, Leonardo, Moreno Velador, Octavio, Figueroa Ibarra, Carlos y Lo Brutto, Giuseppe, Los senderos tortuosos de América Latina, México, BUAP/IcsyH "Alfonso Vélez Pliego", 2014.

Tla-MeldudA, revista de Ciencias Sociales. Facultad de Derecho y Ciencias Sociales. Benemérita Universidad Autónoma de Puebla, México / IssN: 1870-6916 / Nueva Época, Año 8, № 37, octubre 2014 / marzo 2015, pp. 228-234. 
Luis Ángel Ramírez Calvario*

Roberto Pérez Vargas**

No es extraño escuchar cuestionamientos sobre por qué Latinoamérica se mantiene como una zona con amplia desigualdad económica y social en el mundo, pese a los enormes recursos naturales y sociales con los que cuenta. La respuesta a esta pregunta necesita ir más allá de explicar las diferencias entre el norte y el sur del continente; se trata de explicar diversos procesos que han limitado las oportunidades de las naciones latinoamericanas para desarrollarse de manera autónoma y libre. La colonización europea, la evangelización cristiana, el control político de las élites económicas instituidas, la intromisión de agentes externos en los asuntos de la política interior y la división entre centros y periferias del sistema mundial moderno han sido condicionantes definitivas que impiden el pleno desarrollo político, económico y social de los Estados-nación latinoamericanos.

La mayor parte de estos elementos pueden observarse dentro de los diversos textos agrupados en el libro Los senderos tortuosos de América Latina: estado, violencia y rebelión, coordinado por Leonardo Herrera Mejía, Octavio H. Moreno Velador, Carlos Figueroa Ibarra y Giuseppe Lo Brutto. Es una serie de artículos de investigación desarrollados dentro del posgrado en Sociología del Instituto de Ciencias Sociales y Humanidades "Alfonso Vélez Pliego" de la Benemérita Universidad Autónoma de Puebla. Su contenido está dividido en tres apartados; busca dar una visión tanto general como particular de ciertos fenómenos que han marcado la historia de Latinoamérica: América Latina; violencia y rebelión en México y Centroamérica; y finalmente Violencia, Estado y memoria.

Si bien no parece sencillo conjuntar una variedad considerable de temas dentro de una sola obra, en el caso de esta en particular, el objetivo no sólo se consigue, sino que además logra crear líneas de análisis con múltiples elementos que, observados en su totalidad, coadyuvan a la comprensión de los procesos históricos en América Latina. La perspectiva de la obra en su conjunto permite entender a la región como un objeto de estudio con elementos comunes y una mecánica de lucha permanente generadora de síntesis identitarias. De acuerdo con su perspectiva, la historia de las nacio-

\footnotetext{
* Estudiante del séptimo semestre en la Licenciatura en Ciencias Políticas en la Benemérita Universidad Autónoma de Puebla, México (ramirezc.luis11@gmail.com)

** Estudiante del séptimo semestre en la Licenciatura en Ciencias Políticas en la Benemérita Universidad Autónoma de Puebla, México (robbievargas@hotmail.com)
} 
nes latinoamericanas no se puede entender sin considerar los cambios y conflictos actuales e históricos que subyacen a su conformación actual. Una construcción histórica que define, dentro de la compleja configuración de las relaciones de poder, la constitución del Estado-nación latinoamericano y que determina el tipo de sistemas políticos que las sociedades, en la contradicción y el constante conflicto, se ven obligadas a impulsar a través de movimientos sociales y luchas políticas de diversa índole.

El texto inaugural de la obra, denominado "La transformación permanente en América Latina. Formas de Estado y movimientos sociales", de Octavio Moreno, nos hace reflexionar sobre el protagonismo de la sociedad como agente reivindicador del bien común y la participación en la vida política de las naciones de América Latina. El autor identifica cuatro etapas en la construcción de las naciones latinoamericanas a lo largo del siglo XIX y el siglo Xx: Estado oligárquico, Estado populista, Estado autoritario y Estado neoliberal-procedimental. Mientras el Estado oligárquico se caracterizó por el uso interesado de las masas y del propio entramado institucional de Estado para el traspaso de poder de un grupo a otro, el Estado populista reivindicará el papel de la sociedad como máxima entidad por quien trabajar. Por otro lado, el Estado autoritario inicia un proceso de desarticulación social para abrir paso libre a grupos minoritarios de interés particular, al punto de que en el Estado neoliberal-procedimental contemporáneo el Estado termina por girar en torno a los intereses de grupos minoritarios bajo la consigna del libre mercado.

En el segundo texto, "El debate sobre el concepto de cooperación internacional; un análisis de propuestas alternativas", de Giuseppe Lo Brutto, se explica que la concepción de cooperación internacional para el desarrollo (CID) puede manifestar en distintas vertientes: por un lado, puede observarse como un "esfuerzo conjunto entre todos los actores participantes" (p. 40) y, desde una visión crítica, entenderse que el apoyo para el desarrollo de los países receptores coopera en el mantenimiento del propio sistema, generando relaciones de dominación, subordinación y dependencia. Como parte de las propuestas que pueden revertir la trayectoria tradicional de la CID, el autor propone la reconsideración del modelo: debe estructurarse como un concepto que se aleje de los intereses político-económicos, a través de una cooperación que busque el desarrollo conjunto, y en donde la relación Sur-Sur sea eje basal.

Imprescindible en este trabajo es el concepto de cooperación para la desconexión, que sirve para entender la importancia de establecer un nuevo modelo de desarrollo, un cambio estructural que "supedite las relaciones externas a las necesidades internas" (p. 56) y finalmente un cambio estructural interno en el que "las necesidades internas deben supeditarse a las necesidades externas” (p. 56). Por último, el texto nos invita, desde una pos- 
tura de profunda alteridad, a repensar la cooperación internacional para el desarrollo "desde adentro, desde el Sur, porque sólo desde el Sur, desde sus prácticas, se pueden estallar discursos dominantes, convirtiéndolos en otros" (p. 59).

Dentro del segundo apartado, "Violencia y rebelión en México", encontramos el texto "Rebelión, organización sindical y violencia del Estado en lucha de la APPO en 2006", de Carlos Figueroa Ibarra y Leonardo Herrera Mejía, donde tratan de analizar el fenómeno de la APPO como un movimiento social con múltiples matices. Este movimiento, partiendo de una estructura sindicalizada, consiguió conjuntar en un frente común a distintas organizaciones sociales, tras el violento desalojo de la sección XXII de la CNTE el 14 de Junio de 2006 en el Estado de Oaxaca. Pese a que el origen del movimiento se sitúa en la lucha sindical que entabló sección XXII, el malestar general que originó la violencia ejercida en un marco de rebelión, provocó la convergencia de un número considerable de colectivos civiles y sociales que, bajo una estructura organizacional común, establecieron, desde cuatro formas particulares de resistencia, un modelo convergente que unifica a sectores diversos de la población Oaxaqueña contra el autoritarismo estatal.

Continuando con el segundo apartado, "Rebelión universitaria en Puebla (1970-1973). La fractura del cacicazgo Avilacamachista", escrito por Lorena Martínez Zavala, busca destacar el papel del movimiento de la UAP en su lucha contra grupos de poder enraizados en la propia institución y contra las políticas del gobierno estatal. En su intento por rescatar el papel universitario, la universidad fue el blanco de la politización de todos los sectores: por una parte, los afines a las decisiones gubernamentales y, por el otro, el grupo simpatizante del PCM que mantenía una postura crítica y contrahegemónica, producto de, entre otras cosas, los acontecimientos del 2 de Octubre de 1968. En su texto, la autora nos invita a reflexionar sobre un aspecto que permitió el surgimiento del movimiento estudiantil y el fin del avilacamachismo en Puebla: la cercanía, que desde entonces ya existía, del gobierno poblano con los intereses del capital privado nacional e internacional contra los intereses político-económicos a nivel federal.

En el tercer apartado, denominado "Una mirada a la migración en México", encontramos "Entre la bestia y la xenofobia. Violencia contra migrantes en tránsito por México", de Leonardo Herrera Mejía, centrado en la migración como fenómeno natural, que implica en la mayoría de sus manifestaciones actos determinados de agresión. Desde su perspectiva, la globalización y el neoliberalismo deben considerase como elementos que impactan y modifican la información, las necesidades y las posibilidades, y obligan a la migración hacia el norte del continente. Una situación en la cual la intromisión de países centrales en la política interna de las periferias termina por ser un factor determinante en la migración masiva. Por otro 
lado, el autor encuentra dos causas que originan la violencia contra estos grupos migrantes en su paso por México: de índole económica y cultural; la segunda, basada en una fuerte tendencia a la negación del otro, que provoca intolerancia y el estigma de la ilegalidad.

Para finalizar este apartado, Ada Cabrera García presenta su texto titulado "Migrantes mexicanos contra la legislación y sentimiento antimigrante de Arizona. Más de un siglo de confrontaciones en territorio norteamericano", en donde propone analizar el fenómeno mediante cuatro apartados: las luchas, la legislación antimigrante, la aproximación al contexto antiguo y mediante reflexiones personales generadas desde estos ámbitos. Precisa, a su vez, entender, dentro de la lógica del capital, cómo las dinámicas de jerarquización de la fuerza de trabajo imponen mediaciones que obligan a los trabajadores a establecer diferencias nacionales o raciales para aprender a competir y buscar un lugar en el propio proceso de explotación. Este sistema clasifica a partir de características contrapuestas al modelo racial anglosajón. Este modelo también funciona como una herramienta discriminatoria que reduce y niega tanto beneficios como derechos y se construye bajo la idea de división racial, un discurso ideológico que legitima la jerarquización en todas sus formas.

Del tercer y último apartado "Centroamérica. Violencia, Estado y memoria", el primero de los capítulos, de Rodrigo J. Véliz, "Guatemala: la crisis histórica del Estado. Reconfiguración productiva, pugnas y represión en el último lustro", nos presenta el papel desvinculador y radical del neoliberalismo en países centroamericanos. Ejemplificado a través del caso guatemalteco, nos muestra cómo el modelo instaurado desde 1979 ha demostrado efectos terribles en la zona, devastando recursos naturales, explotando al trabajador y manteniendo una distribución desigual de la riqueza. A través de un análisis específico, se muestra la importancia de los partidos políticos para entender la situación actual del modelo neoliberal.

En el caso guatemalteco, el partido Socialdemócrata parecía ser el cambio necesario; sin embargo, resultó en una izquierda burocratizada, concentrada en mantener los intereses del mercado sin reformas y cambios sustantivos. A través de este análisis, podemos comprender cómo resulta complicado, dados los intereses del capital nacional e internacional, que grupos de representación popular o de izquierda lleguen al poder en Guatemala por razones similares a las de México: los acuerdos y pactos firmados durante la primera década del siglo Xxi han demostrado que el principal interés de las élites guatemaltecas es mantener una política neoliberal, beneficiosa para pocos y destructiva para muchos.

El octavo artículo, titulado "Medios, memoria y política en el norte de Morazán. Espejos digitales y la cambiante imagen de la historia entre los hijos de la guerra civil salvadoreña”, de Rafael Alarcón Medina, es un 
ejercicio de reflexión sobre los movimientos sociales y su papel histórico como agentes que alteran positivamente la realidad. El problema de algunos movimientos, que surgen como elementos de cambio, radica en que tras el proceso por el cual obtienen la victoria, el recuerdo pierde concreción, se mitifica, se abandona al olvido, considerando irrepetibles las circunstancias que lo generaron, debido a los constantes cambios de la sociedad. Las generaciones partícipes de tales manifestaciones no olvidan su papel en la confección de la historia; pero, ¿en quién recae la responsabilidad de trasmitir la misma voluntad de lucha a las nuevas generaciones, inmersas en constantes innovaciones tecnológicas? Para el autor es indispensable destacar el papel del Estado hegemónico y resaltar la función de los medios de comunicación como reproductores ideológicos. La responsabilidad de las nuevas generaciones se centra en seguir transmitiendo el mensaje que invita a la reflexión sobre la lucha armada: cambiar el estado actual implica negar el uso de la violencia como una alternativa, la herramienta del diálogo debe priorizarse por encima de la brutalidad.

Para finalizar, Olga Alicia Paz Bailey nos presenta "La violencia sexual en Guatemala: un conflicto pendiente", en donde se subraya que uno de los factores necesarios para la ejecución sistemática de la violencia hacia la mujer se encuentra en el régimen autoritario generado por el conflicto armado que vivió Guatemala durante 36 años, y en donde el abuso sexual cometido por militares en contra de cientos de mujeres, en su mayoría indígenas, fue utilizado como estrategia de guerra, principalmente entre 1980 y 1983.

Resulta interesante examinar que, bajo la división bipolar del mundo durante la guerra fría, la amenaza del fantasma comunista permitió que muchas naciones justificaran el establecimiento de totalitarismo en el afán de escapar de esta amenaza ideológica, y que bajo esta misma dinámica, la crueldad contra la población civil no tuviera paragones, transgrediendo y marcando permanentemente a cientos de mujeres. Paz Bailey realiza diversas propuestas para comprender las variables deontológicas que pueden explicar el comportamiento del individuo transgresor. Hace un análisis de la personalidad autoritaria, tomando como referencia algunos postulados de la teoría crítica, que proponen rastrear desde etapas tempranas del desarrollo humano los orígenes la violencia. La autora también pone especial atención en la construcción social de los actos de dominación, pues "el ejército responde a la sociedad que lo ha formado" y por ello resulta obligado entender la ideología, cultura e historia de la sociedad.

Consideramos que el texto analizado presenta y propone valiosas categorías de análisis a través de los diferentes textos. Las temáticas abordadas nos remiten, sin duda, a los diferentes tipos de violencia que han dejado cicatrices permanentes en la historia latinoamericana. Por otro lado, si se apela con urgencia a la necesidad de observar en las sociedades contemporáneas de 
América Latina, en el texto se vislumbran diferentes factores que posibilitan abrir espacios. En este sentido, los movimientos sociales, más allá de constituirse como simples herramientas generadoras de catarsis colectiva, demuestran una funcionalidad que modifica la naturaleza democrática de los pueblos, aún si tales manifestaciones en sus orígenes no parecen adecuarse de lleno al descontento legítimo de todos los estratos vulnerables de la sociedad. Como herramienta de análisis académico, la presentación de los fenómenos que se ilustran dentro de Los senderos tortuosos de América Latina puede apelar a esa indignación que concrete la necesidad de una praxis social, y a una nueva transformación. 